\title{
DIGITALLY CHANGING TEACHING PRACTICE ENVIRONMENTS: AN EXPLORATION OF CONCEPTS AND IMPLICATIONS
}

\author{
Marloes de Munnik ${ }^{1}$, \& Osama Al-Mahdi ${ }^{2}$ \\ ${ }^{1}$ Centre for Researching Education and Labor, University of the Witwatersrand $/ P h D$ fellow \\ (South Africa) \\ ${ }^{2}$ Educational Studies Department, Bahrain Teachers College, University of Bahrain \\ (Kingdom of Bahrain)
}

\begin{abstract}
This paper proposes using different concepts for guiding institutional practices in times of digitally changing professional teaching work environments. This paper draws upon our previous research and offers a first step of a framework, to understand and explore the new digital changes for professional teaching and learning practice, while engaging in online and virtual work and learning environments. Thereby focusing on the notion of a professional and the social implications of digital work technologies that are used for teaching and learning. The theoretical paper is structured around concepts we identified in our previous work and its potential of adopting them in the context of digital communities of professional practices. Addressing these objectives can hopefully help us to understand, what the effects of digital professional teaching work environments on teaching practice and for teacher's professional responsibility are, their social effects in everyday teacher work and their practice related knowledge? What capabilities, features or skills are enabling teachers to do so and what guidelines can help them to cope with the current changes? And ultimately, how workplaces, schools and universities can benefit from these ideas? We focus on both human social factors and digital material factors as being inherent to professional teaching and learning practice. We hereby build upon concepts derived from socio-cultural and socio-material theories which are currently not commonly used in the same context, such as: communities of practice which is popular in socio-cultural learning theories whereby the understanding of human development relies on the social world; and extending the community of practice with materiality whereby human development also involves the material world. We contribute with this paper by suggesting that our framework, drawing on concepts of two different but related learning theories is useful for further research, such as on the institutional and individual response to digital change in teaching and learning practice. We believe that our theoretical informed conceptual approach enables to inform an increased professionality of teaching professionals in times of digital work change, activates thinking about different concepts, a change of mindset or at least provide the guidelines for an improved understanding among those involved in teaching practice.
\end{abstract}

Keywords: Education, communities of digital practice, professional practice, digital technologies, participatory learning practices.

\section{Introduction}

The Covid-19 pandemic has forced humanity to adapt to digital change as never before. The pandemic has forced individuals to look beyond traditional approved approaches for working and changed the generalized appetite for digital advanced ways of working. The digital change implications of the fourth industrial revolution are believed impacting work and have implications on individual workers at various levels (International Labour Organization, 2015; Schwab, 2016). An example of accelerated change that has happened during the current Pandemic, is that more individual professionals were forced into a work ecosystem with digital technologies. People were namely, forced into a situation of remote work and had to work with digital technologies to support them in this way of working. For instance, the digital technologies played a role in executing work practices directly and in communicating with people. Some of the changes are directly automating or innovating traditional work techniques and processes. For example, teachers were forced into online teaching and academic institutions which were previously reluctant to change, were forced to adjust their standpoint and adapt to the required change by exploring less-traditional ways of working. The rapid changes and new trends in our environments resulted in digital technologies being further invited in our work and learning environments. This resulted in them being strongly embedded in both. Fenwick \& Edwards (2016) suggest that a lack of detailed research 
about digital technologies and effects on professional responsibility exist and we believe that adding a conceptual framework to understand institutional teaching practices in times of digital change would contribute to this gap. This paper draws upon our previous research (de Munnik, 2020), (Al-Mahdi \& Alwadi, 2015) and offers a first step of a framework to understand and explore the new digital changes for professional teaching practice and changing professional teaching work environments, drawing on and merging ideas from sociomaterial and sociocultural theories. The paper is structured around concepts that may help to answer questions such as, what are the implications of digital technology in teaching practice for teacher's professional responsibility, their social effects in everyday teacher work and their practice related knowledge? What capabilities, features or skills are required from teachers and what frameworks or theories can help them to cope with the current changes? And ultimately, how workplaces, schools and universities can benefit from these ideas? Given the variance in the topics of investigation and the multidisciplinary nature, the modest contribution we make is therefore, not intended to be a comprehensive research, a literature review, or purely academically centered suggestion. In fact, our suggestion rather relies on acting as an exploratory conceptual starting point, drawing selectively on literature in sociocultural and sociomaterial theories and taking an ontological approach of the existence of multiple realities instead on one ultimate scientific truth. Ultimately, we hope hereby to contribute to a discussion and stimulate to look beyond stabilized and commonly accepted approaches which could enable diverse ways of dealing with learning and teaching in times of digital change. Our position is that digital technologies must be seen as professional enhancing aspects (de Munnik, 2020) rather than threats, are contributing value to professional teaching practices and are resulting in emerging possibilities for creating innovative learning and teaching contexts. We hereby acknowledge that digital technologies may pose challenges for both individuals as well as organizational practice, but we see these as small obstacles to overcome considering their strong positive value proposition. This thought-provoking theoretical paper discusses how sociocultural and sociomaterial approaches can be used to understand the importance of adapting to change for teaching professionals in a changing digital work context - and the possible social implications of digital change for teaching professionals.

\section{Theories and concepts}

Various learning theories and traditions in the field of education exist and change over time. One of which is a conceptualization of how people think and act, developed by the sociocultural school of thought. The primary set of principles of this theory were developed by Vygotsky (1978) and his colleagues and a multitude of scholars around the world (e.g., Lave \& Wenger, 1991; Moll et al., 1992; Rogoff, 1990; Tharp \& Gallimore, 1988). This theory suggests that human development requires an understanding of the extended social world. It is impossible to understand cognitive development by just studying the individual; the extended social world of the learner must be taken into consideration because focusing only on the individual may divide human functioning into smaller units that no longer work as does the larger living unit (Rogoff et al., 2003; Rowe \& Wertsch, 2002; Siegler \& Alibali, 2005). Furthermore, the sociocultural theory suggests that human cognitive development is influenced not only by social interactions, but also by cultural tools. These tools divide into several categories including: material tools (e.g., calculators, computers, or smart phones) and symbolic systems (e.g., spoken and written language, signs, symbols, number systems, rituals, models of behaviors, scientific concepts, and techniques that assist memory in thinking). These tools influence the way people organize, process, and remember information. In the sociocultural view, learning is regarded as a process that occurs in a larger context where knowledge has a functional importance for the learner and this process of linking the individual understanding with the wider context can aid the learner in achieving his or her personal goal that is socially valued within the community. Thus, learning is not seen as just a separate activity undertaken for its own sake in the sociocultural perspective (Wells, 1999). The sociocultural theory was utilized as a perceptive and practical framework for examining various educational, social and psychological phenomena in a plethora of research in different parts of the world. Lave and Wenger (1991) proposed the concept of 'situated learning' and learning through participation in the 'community of practice'. Communities of practice was a trend in learning for work theories which is different from traditional understandings of learning found in cognitive-behavioristic theories, according to Lave and Wenger (1991); it relied on human collaboration as a rudimentary wheel for learning and learning is conceptualized as a social event. To conclude this section about sociocultural theories, we can establish that the experience of 'learning' itself is a complex process and, thus, can be approached through different perspectives. More recent views define learning as a social process that involves participation in learning communities through social interactions with humans and materiality, and this perspective shall be given more focus in the following sections.

In later years, the concept of social communities of practice was expanded upon and new learning theories, both including participating humans and materiality emerged. Materiality is hereby understood as the involvement of other participants beyond humans, whereby materiality such as objects, tools, technologies, and processes are participating in the work practice and have an active role in the 
process of this work practice. The theoretical approach in which this materiality received further acknowledgement, beyond being non-participating constituents of a work practice, were those of sociomaterial theories (Fenwick et al., 2012). Sociomateriality here is referring to different theories of work such as Actor Network Theory [ANT] (Latour, 2005), post-humanism, and the practice-theory (Nicolini, 2012). Critiques of the sociomaterial theory and related approaches often tend to refer to the false allocation of agency to materiality. However, following one of the main historical figures in ANT, Latour, no upfront agency is allocated to any member or actor of the practice (Latour, 2004) but all are considered relevant in the practice network. In sociomateriality, humans are found to perform together with all actors in a practice, both human and nonhuman. Performing is hereby understood as a work-related activity that changes and relies on the specific context. We are thereby drawing on Barad (2003) and asking questions about professional accountability and responsibility. Each practice participant then contributes in its own way, both considered and accidentally to the development of that specific work practice. The degree of this individual professional contribution relies on the concept of the 'enactment of boundaries' following Barad (2003) and in advanced ways through application or change (Orlikowski, 2000). Enactment used here, thus means that those professionals who are engaging in a digital technology impacted work context, may act in varies ways. And as such, the impact on their work, as well as how they use, and negotiate professional agreements with digital technology varies. In any case of working with other participants in a work practice, the professionals must 'translate' their actions and 'mobilize' (Callon, 1984) and negotiate to reach a common agreement or achieve a "dynamic stability" (Scoles, 2017, p. 83). To conclude, sociomaterial approaches are relevant to the current context since professionals must work in a digital work environment, thus theories acknowledging their participating role are required. Since the Covid-19 pandemic forced professionals to work in unusual ways together, communities of work practice thereby move beyond human constitutions only and are including digital technologies. The digital technologies, which are thus a form of materiality, are having an impact on professionals and their professional responsibilities (Elliott, 2017; Fenwick \& Edwards, 2016) based on the notion of their considered participation in a work practice. Nevertheless, we suggest that while including digital technologies as considered participating members in the practice while leaving space for human collaboration and their professional practice argues for maintaining the social aspects as found in sociocultural theories which combination is what we suggest for a conceptual framework.

\section{Sociomateriality considered in digital communities of professional teaching practice}

To illustrate the idea of technology and materiality we are focusing on engineers as exemplars of professionals working in a digital technology impacted work environment and conceptualize the application to teachers later on. Whereby we are assuming, that while their professional responsibilities and ability to enact upon digital technologies may vary, as well as their 'negotiated' agreements, the principles of applying a sociomaterial informed conceptual framework are similar. This is based on them both being semi-regulated professions, relying on an agreed and regulated body of knowledge (Abbott, 1988) and therefore subject to perform successful negotiations for reaching a common agreement. Abbott suggest that professions are relying on the control of knowledge and skill and the regulation of techniques (practices) and are therefore "more likely resistant to change" (de Munnik, 2020, p. 9) their agreed body of professional knowledge. This agreed body of professional knowledge relies on accepted standards agreed over time among professional bodies and groups and may feed into the delay between changes in work and professional practice and required skills, skills here are understood to be both residing in humans and work (McGuinness et al., 2017).

In the professional context of engineering, recent research (de Munnik, 2020) applied the concepts of performing and enactment to two specific engineering work practices, namely, preparing project reports and developing construction plans. The professional responsibilities of the engineering professionals in the research were shared or were changing in the digital technology context. The engineering work practice was then termed an unique sociomaterial networked relative "stability" (Scoles, 2017, p. 196), since the engineering work practice was not static and similar in each context. This resulted in the understanding that learning opportunities for the engineering professionals were developed, based on the performing of each sociomaterial member of that engineering practice (de Munnik, 2020) or the successful 'enactment' upon each other. Hereby, the former applies to our earlier suggestion that of a professional practice being sociomaterial, whereas the latter refers to the notion of a social cultural community of practice.

The sociomaterial members of the work practice are performing themselves into meaningful action. Thus, also digital participants may change the work practice directly and indirectly. This change can be caused by the task/skill complementary or replacing capabilities of digital technologies. Digital capabilities may be exceeding the level of human capabilities. Such as those identified by Elliott (2017), suggesting that some technological systems are able to perform the reasoning of information, found to be closely to the identified existing human reasoning abilities. This subsequently result in digital technology's enhancing power for professional decision-making work of humans by using reasoning in 
the process. We therefore suggest that both social and material have a significant participating role in a work practice and may define and guide its associated learning. Next, we explore the digital impacted network of professional practice.

In the same research (de Munnik, 2020), simulation as a digital technology was found as a part of this particular network of the engineering professional work practice of preparing project reports, namely, for $35 \%$ of the 41 engineering professionals. A detailed sociomaterial tracing of the practice network of one particular engineering professional, which relied on the perception that practitioners were being trustworthy expert informants (Mulcahy, 2013), showed the important role of simulation in the sociomaterial network of this particular professional. The network showed that simulation was part of the engineering work practice and the connections to both other actors, actions and learning illustrated that the professional experienced both social and material implications from this shared participation. The engineering professional was in fact sharing his/her professional responsibilities with digital technology. The implications for the respective engineering professional were that boundaries were being pushed and more was possible in fewer time and with an increased quality (de Munnik, 2020).

Simulation is also used in teacher practices, such as by imitating a realistic learning environment and simulating a specific professional action of the learner in its situated environment or also differently used in teaching scientific concepts through Virtual Reality. In essence, a teacher is then both a provider in this digital community, and at the same time a professional participant which requires us as teachers to reconsider our social role into a sociomaterial role.

Imagining working in an Artificial Intelligence [AI] impacted environment. AI is hereby understood as the performing of "human-like cognitive functions" (Organisation for Economic Co-operation and Development, 2017, p. 25) by systems and devices. AI has the potential for further sharing of professional responsibilities and may further accelerate change in our professional work practices. This in turn requires us to perform differently, relying on our successful abilities to enact upon the digital participants such as AI. This means that our current digital capability status may require improvement, as well as our broader skills, and at the least, we should inform ourselves about digital capability developments to allow for a successful further sharing of professional work responsibilities for both ourselves and for our students. The implications for learning for a digital work practice approached with the conceptual framework of a community of a social material practice can help professionals to understand that lifelong learning is key. Learning for professional practice can thus not end, is continuous, unique and context dependent. For professional upskilling and reskilling discussions, this means that professional development is required when changes of the work context, environment or in participating sociomaterial members happen. Participating in a work practice is performing ones own existence and translate own knowledge and skills in the sociomaterial digital-human community, as well as the ability to come to mutual agreements with other actors in the practice. To illustrate, being a teacher thus requires not only considering the social aspects of one's own professional practice and learning and teaching, but also requires considering the materiality of learning (Mulcahy, 2012; Sørensen, 2009).

\section{Conclusion - How work and learning stakeholders may benefit from the ideas of sociomaterial communities of practice}

The strength of sociomaterial theories is that the approaches drawing on them, allowing to see the social effects of a digital impacted practice. For example, such as online learning and teaching. A practice which is taking place in a virtual community with both human and non-human participants (e.g. digital technology). Adopting a sociomaterial approach, the focus shifts away from seeing online learning as an own and practice changing event, to an activity in which both human and digital actors are taking part and creating learning opportunities. This may help to see our professional learning for work professional teaching- practice as something we need to sociomaterial collaboratively participate in, and which keeps changing and evolving. Recommendations for education and learning for work may move beyond traditional understandings of school-based only. Models such as work-based learning with the "importance of exposure and participating in practice and experience" (de Munnik, 2020, p. 225) may become increasingly valuable in times of digital changes. In Work based learning, adapting to change is through developing in practice all the time and thereby, acknowledging learning for professional practice as an 'unique relative stability' (de Munnik, 2020; Scoles, 2017). Learning is not an individual event but something that requires consideration of an active participation of a work practice in the 'real' context and with all, both direct and mediating participating members who have to negotiate to come to common agreements in the work practice. Further questions we can ask and answer with using the new proposed sociomaterial conceptual frameworks in the digital context, are therefor: Whether or not, the accelerated digital changes resulting from the Covid-19 pandemic have resulted in professionals' knowledge and skills set suitable to deal with these changes or allowing the professionals to enact upon the technologies? - Have professionals in semi-regulated professions been able to adapt to the change required of them, and in what way have they been limited by the possible regulations or agreed body of knowledge in their professions? 


\section{References}

Abbott, A. (1988). The system of professions: An essay on the division of expert labor. University of Chicago Press.

Al-Mahdi, O., \& Alwadi, H. (2015). Towards a sociocultural approach on teachers' professional development in Bahrain. Journal of Teaching and Teacher Education, 3(1), 89:100.

Barad, K. (2003). Posthumanist Performativity: Toward an Understanding of How Matter Comes to Matter. Signs: Journal of women in culture and society, 28(3), 801-831.

Callon, M. (1984). Some Elements of a Sociology of Translation: Domestication of the Scallops and the Fishermen of St Brieuc Bay. The Sociological Review, 32(1_suppl), 196-233.

de Munnik, M. (2020). Exploring learning for work in the context of digital work technologies: The sociomaterial case of engineering professionals in the construction industry (Unpublished doctoral dissertation). University of the Witwatersrand, Johannesburg South Africa.

Elliott, S. W. (2017). Projecting the impact of information technology on work and skills in the 2030s. In C. Warhurst, K. Mayhem, D. Finegold, \& J. Buchanan (Eds.), The Oxford handbook of skills and Training (pp. 557-575). Oxford University Press.

Fenwick, T., \& Edwards, R. (2016). Exploring the impact of digital technologies on professional responsibilities and education. European Educational Research Journal, 15(1), 117-131.

Fenwick, T., Nerland, M., \& Jensen, K. (2012). Sociomaterial approaches to conceptualising professional learning and practice. Journal of Education and Work, 25(1), 1-13.

International Labour Organization. (2015). World Employment and Social Outlook 2015 - The changing nature of jobs (13.01.3; p. 155). ILO.

Latour, B. (2004). Why has critique run out of steam? From matters of fact to matters of concern. Critical Inquiry, 30(2), 225-248.

Latour, B. (2005). Reassembling the Social: An Introduction to Actor-Network-Theory (1st ed.). Oxford University Press.

Lave, J., \& Wenger, E. (1991). Situated learning: Legitimate peripheral participation. Situated Learning: Legitimate Peripheral Participation, 138-138.

McGuinness, S., Pouliakas, K., \& Redmond, P. (2017). How useful is the concept of skills mismatch? International Labour Office.

Moll, L., Amanti, C., Neff, D., \& Gonzalez. (1992). Funds of knowledge for teaching: Using qualitative approach to connect home and classroom. Theory into Practice, XXXI (2), 132-141.

Mulcahy, D. (2012). Thinking teacher professional learning performatively: A socio-material account. Journal of Education and Work, 25(1), 121-139

Mulcahy, D. (2013). Turning Around the Question of 'Transfer' in Education: Tracing the sociomaterial. Educational Philosophy and Theory, 45(12), 1276-1289.

Nicolini, D. (2012). Practice theory, work \& organization. Oxford University Press.

Organisation for Economic Co-operation and Development. (2017). OECD Digital Economy Outlook 2017. OECD Publishing.

Orlikowski, W. J. (2000). Using Technology and Constituting Structures; A Practice Lens for Studying Technology in Organizations. Organization Science, 11(4), 404-428.

Rogoff, B. (1990). Apprenticeship in thinking: Cognitive development in social context. Oxford University Press.

Rogoff, B., Paradise, R., Arauz, R., Corra-Chavez, M., \& Angellio, C. (2003). Firsthand Learning through intent participation. Annual Review of Psychology, 54, 175-203.

Rowe, S., \& Wertsch, J. (2002). Vygotsky's model of cognitive development. In U. Goswami (Ed.), Blackwell handbook of childhood cognitive development (pp. 538-554). Blackwell Publishing.

Schwab, K. (2016). The fourth industrial revolution. Penguin.

Scoles, J. (2017). Exploring professional engineers' knowings-in-practice in an emerging industry: An Actor-Network Theory approach (Doctoral dissertation University of Stirling), retrieved from https://dspace.stir.ac.uk/handle/1893/26857\#.YCTAyugzY2w

Siegler, R., \& Alibali, M. (2005). Children's thinking (4th ed.). Parson Education International.

Sørensen, E. (2009). The Materiality of Learning: Technology and Knowledge in Educational Practice. Cambridge University Press; Cambridge Core.

Tharp, R., \& Gallimore, R. (1988). Rousing minds of life: Teaching, learning and schooling in social context. Cambridge University Press.

Vygotsky, L. (1978). Mind in society: The development of higher psychological processes. Harvard University Press.

Wells, G. (1999). Dialogic inquiry: Toward a sociocultural practice and theory in education. Cambridge University Press. 